\title{
THE END OF OIL AND ITS IMPACT ON NATIONAL AND COLLECTIVE SECURITY
}

\author{
Ionuţ Alin CÎRDEI \\ "Nicolae Bălcescu" Land Forces Academy, Sibiu, Romania \\ cirdei_alin@yahoo.com
}

\begin{abstract}
Today's society is heavily dependent on fossil energy resources and especially on oil, which is the basis of the entire transport system and beyond. The need for energy resources will increase with the passage of time, in the context in which the population of the world grows, and the fulfillment of its basic needs implies an increasing consumption of energy. The fossil energy resources are in finite quantity, and their depletion is a matter of time, even if the moment when they will disappear is quite remote, due to the discovery of new deposits, the improvement of extraction technologies, etc. The depletion of fossil energy resources can be a major challenge for all states that will have to take measures for a smooth transition to the use of new energy sources that are supposed to cover the needs of society and at the same time to have a small impact on the environment, in an attempt to reduce the pace of climate change.
\end{abstract}

KEYWORDS: oil, energy security, renewable energy, exhaustion

\section{Introduction}

The availability of energy resources is a topic of great interest to the international community, whether we are talking about policy makers, business people or the population, because today's society is increasingly dependent on energy, and especially on energy from hydrocarbons. The issue of the availability of energy resources which represent the basis of the functioning of the states and the economy and a guarantor of the well-being of the population is a real problem, which has an impact on the individual and state security. The history of humanity itself can be analyzed from the perspective of the progressive development of new energy sources, as well as of the specific exploitation technologies, which together have been the basis of the increase of the global standard of living, the improvement of the living conditions and implicitly the increase of the population number (Hall et al, 2003), which has led to an increase in the demand for energy resources and the entry into a vicious circle in which the need for resources pushes humanity towards the discovery of new technologies and new sources of energy, and this race of ensuring the energy resources has consequences in terms of national and collective security, both directly, due to the aspects related to the relations between states and the imperative to reach the objectives, due to the new power relations that are established, and indirectly, through the impact that human activities have on the environment and due to the acceleration of climate change, which affects the individual and collective security. 


\section{Peak Oil and the Problem of Oil Resources Depletion}

Conscious of the importance of energy resources, the states have developed energy security strategies and tried to provide the necessary resources, in sufficient quantities, at affordable prices and with a constant flow. Any disruption of the supply of energy resources, whether due to natural factors, or to tensions or conflicts in the extraction zones or on the transport routes, or to the intimidation policies adopted by the states, has immediate consequences at regional or global level and can cause a deterioration of the general state of security and an increase in international tensions.

Oil is one of the most important energy resources for today's society, representing the foundation of transport systems worldwide and the basis of the functioning of the world economy. From this perspective, with the increase of the oil consumption, the people posed the problem of its depletion and various theories and scenarios were elaborated that had in the foreground the consequences of its depletion. Thus, in 1956 Hubbert M. King, a well-known researcher in the United States issued the theory called "peak oil theory", according to which the United States oil production will reach the peak in the period 1966-1972 (Fusco, 2006), and after this moment the production will decrease. His prediction proved true, this moment materializing in 1970. Based on this theory, various researchers have expanded the scope and tried to predict the attainment of this peak of production worldwide and hence to anticipate the end of the oil age, an event that would throw humanity into chaos and have the most serious consequences in all areas. However, this theory has some limitations and starts from the idea that the peak of production can be calculated at one point, taking into account a series of parameters that are more estimative, correlated with the level of technology development and with the anticipation of future consumption. Thus, in order to calculate the availability of oil resources, the quantity of oil that can be extracted using current technology is taken into account correlated with the consumption rate and the ratio between the cost of production and the cost of selling. In reality, this theory does not attempt to predict when oil resources will run out, but when their use would no longer be accessible or cost effective. Calculating when the peak is reached is actually extremely difficult to achieve, as technology evolves and the discovery of new oil fields changes the whole situation. It can be noticed that there are numerous researches conducted by entities in the field, such as Cambridge Energy Research Associates (CERA), the International Energy Agency (IEA), BP, Shell, the Energy Information Administration (EIA), the Energy Watch Group, which considers that "peak oil" will be reached, at global scale, somewhere between 2017 and 2035, without being able to provide a more accurate estimate (Chapman, 2013). What seems to be accepted by most research, however, concerns the availability of global oil resources, which, based on current consumption and taking into account the discovery of new deposits and the development of new technologies that make it possible to extract oil from the areas and through processes that previously it was not possible, estimates that the oil resources will be exhausted in about 50 years. According to the available statistical data (ENI, 2019) the world oil reserves as of December 31, 2018 were sufficient to ensure consumption for 48 years, as shown in Table no. 1. From the analysis of the available data, taking into account the current level of consumption, it can be observed that, worldwide, the availability of oil resources increased from 45 to 48 years, between 2000 and 2018, due to the discovery of new deposits and the use of new technologies in 
the extraction process. Also, the availability of oil reserves can be influenced by certain destructive or catastrophic events, such as the case of Syria, which in 2000 had oil resources that would have been sufficient for 11 years at the rate of extraction at that time, and in 2018, the available resources were sufficient for 285 years, both due to the new discoveries and to the reduction of the extraction rate due to the conflict that is crushing this country. A similar situation can be identified in Yemen, which recorded a change in the availability of resources from 15 to 205 years, in the same period of time.

Table no. 1

Availability of known oil reserves (measured in years)

\begin{tabular}{|l|c|c|}
\hline \multirow{2}{*}{\multicolumn{1}{|c|}{ Region }} & \multicolumn{2}{c|}{ Available reserves (in years) } \\
\cline { 2 - 3 } & Year 2000 & Year 2018 \\
\hline Europe & 8 & 11 \\
\hline Russia and Central Asia & 20 & 22 \\
\hline Middle East & 81 & 69 \\
\hline Africa & 33 & 39 \\
\hline Asia - Pacific & 13 & 18 \\
\hline America & 43 & 52 \\
\hline World & $\mathbf{4 5}$ & $\mathbf{4 8}$ \\
\hline
\end{tabular}

In the mentioned time period it is possible to see a continuous increase of the oil consumption, which, according to the same source, from the value of 75209 thousand barrels of oil per day in the year 2000 , to a consumption of 95150 thousands of barrels of oil per day in the 2018 registered worldwide. In the future, due to the measures taken to reduce carbon emissions and to reduce dependence on hydrocarbons, it is possible to witness a decrease in oil consumption, even if total energy consumption will increase. This evolution will have consequences for the security of states and regions, which must adapt dynamically to these trends. EU states are committed to reducing dependence on hydrocarbons and moving to a low-carbon economy, which means that countries whose energy security is based on oil extraction and trading will have to work to diversify the economy and to reduce their own energy vulnerability. If this transfer, with all its consequences is not made on the basis of a long-term plan, it is possible to witness an increase in tensions in certain regions of the world, internal disturbances due to the decrease of the standard of living or even confrontations between states.
Ensuring long-term energy security is a major challenge due to "the controversial nature of this concept, which is based on the overlapping of political, economic, technical and environmental aspects, as well as on the legal dimension that regulates energy transport and transfer processes" (Elbassoussy, 2019, p. 323). Energy security at national or collective level cannot be ensured through individual efforts, both due to the high costs and the fact that the distance between the areas of production and those of consumption of energy resources is large, and the security of the whole system must involve more states, whose interests must be complementary and the approach must be common. Energy security can be approached as an individual problem, of each state, but the solution of this problem must be shared. Even if some interests may be divergent at some point, and energy resources may be used as a weapon or as a tool of pressure in international relations, each actor must be aware that this approach can only ensure short-term benefits, and that long-term consequences of this attitude and the impact on security can be difficult to anticipate and manage. 


\section{Position of the European Union on Reducing the Share of Oil in the Energy Mix}

Energy security means providing the necessary resources for the proper functioning of the economy and society as a whole, by maintaining a continuous flow of energy resources, at affordable prices and in the required quantities, taking into account the least impact on the environment, which is increasingly most affected by human activities. The security of energy supply depends on a number of factors, such as (Elbassoussy, 2019, p. 328): the availability of energy reserves, both from internal and external sources, the ability of the economy to attract the necessary energy resources, the degree of diversification of the energy resources used and energy resource providers, accessibility of energy resources through the diversification of energy transport and storage infrastructure, the geopolitical context that can influence access to energy resources.

EU energy security is highly vulnerable due to the high degree of dependence on imported energy resources. Thus, at the end of 2018, according to the data available on Eurostat, it is found that the total dependence of the EU on the imported energy resources is $55.7 \%$, while the dependence on oil is $86.6 \%$, in the whole Union existing only 3 states whose dependency is below 80\%: Denmark $(19.24 \%)$, Great Britain (28.47\%) and Romania (62.3\%). If we also take into account the origin of oil imports throughout the European Union, we can see that out of the total imported oil, most come from relatively few sources, so at the end of 2017 the main oil suppliers for EU countries were: Russia (30.7\%), Norway (11.4\%), Iraq (8.2\%), Kazakhstan (7.4\%), Saudi Arabia (6.6\%) and Nigeria (6.4\%), accounting for over $70 \%$ of the total imported oil. A similar situation is registered in the case of natural gas, which is supplied in proportion of $81.9 \%$ by only
4 states and in the case of coal, which is supplied in proportion of $88.4 \%$ by only 5 states. The data presented above gives us a fairly clear picture of the EU's vulnerability to external energy sources, especially considering the fact that Russia is the main partner in providing all the types of energy resources listed above, with a weight of at least $30 \%$ for each of them. The EU's dependence on Russia is mutual, and none of those two actors is interested in stopping the flow of energy resources, but external factors that can affect or even disrupt the supply flow can occur. Considering that the EU is one of the largest consumers of energy resources and the fact that internal resources are extremely low, the EU strives to diversify the energy mix by using as many types of energy resources as possible, in parallel with the diversification of suppliers and transport routes, to reduce vulnerability to any accidental or intentional disruption of supply. In parallel, in order to reduce dependence on fossil energy resources and to reduce the impact of human activities on the environment, the EU has set its target to reduce greenhouse gas emissions by $80-95 \%$ by 2050 , having as reference level the greenhouse gas emissions of 1990. This is possible only by using energy from renewable sources in proportion of at least $75 \%$ of the total energy consumption by 2050 and by promoting an increase in the share of electricity obtained from renewable sources up to $97 \%$ of the total by 2050 (European Commission, 2012). Diversifying the energy mix of EU states and increasing the share of energy from renewable sources, seen as a reduction of vulnerability to external sources of supply and a measure to strengthen energy security was a priority for policy makers. Thus, in 2009, a European directive was drafted (Directive 2009/28/EC, 2009), which stated that the Member States should increase the share of renewable energy used up to $20 \%$ of the total energy consumed by the year 2020. Subsequently, this directive 
was amended by another directive (Directives 2018/2001, 2018), and the target for 2030 was set to at least $32 \%$ clean and renewable energy consumed at Union level, but not all states are required to meet this target, because it is taken into account the national specificity and each country potential. According to the available statistical data (Eurostat, 2018), at the end of 2018 the EU was close to the target of $20 \%$ of the share of energy from renewable sources, the value being $18 \%$, but having states that exceeded this value, such as: Bulgaria, Denmark, Estonia, Croatia, Latvia, Lithuania, Austria, Romania, Slovenia, Portugal, Finland, Sweden, some of them even exceeding the individual quota set for 2020, as shown in Table no. 2.

Table no. 2

The share of energy from renewable sources from the total energy consumed at EU level (data retrieved from Eurostat)

\begin{tabular}{|c|c|c|c|c|}
\hline & & 2009 & 2018 & 2020 target \\
\hline EU28 & EU28 & $12,6 \%$ & $18,0 \%$ & $20,0 \%$ \\
\hline $\mathbf{B E}$ & Belgium & $4,7 \%$ & $9,4 \%$ & $13,0 \%$ \\
\hline BG & Bulgaria & $12,0 \%$ & $20,5 \%$ & $16,0 \%$ \\
\hline $\mathbf{C Z}$ & Czech Republic & $10,0 \%$ & $15,1 \%$ & $13,0 \%$ \\
\hline DK & Denmark & $20,0 \%$ & $36,1 \%$ & $30,0 \%$ \\
\hline DE & Germany & $10,9 \%$ & $16,5 \%$ & $18,0 \%$ \\
\hline EE & Estonia & $22,9 \%$ & $30,0 \%$ & $25,0 \%$ \\
\hline IE & Ireland & $5,2 \%$ & $11,1 \%$ & $16,0 \%$ \\
\hline EL & Greece (estimated) & $8,7 \%$ & $18,0 \%$ & $18,0 \%$ \\
\hline ES & Spain & $13,0 \%$ & $17,4 \%$ & $20,0 \%$ \\
\hline $\mathbf{F R}$ & France & $12,2 \%$ & $16,6 \%$ & $23,0 \%$ \\
\hline HR & Croatia & $23,6 \%$ & $28,0 \%$ & $20,0 \%$ \\
\hline IT & Italy & $12,8 \%$ & $17,8 \%$ & $17,0 \%$ \\
\hline $\mathbf{C Y}$ & Cyprus & $5,9 \%$ & $13,9 \%$ & $13,0 \%$ \\
\hline $\mathbf{L V}$ & Latvia & $34,3 \%$ & $40,3 \%$ & $40,0 \%$ \\
\hline $\mathbf{L T}$ & Lithuania & $19,8 \%$ & $24,4 \%$ & $23,0 \%$ \\
\hline $\mathbf{L U}$ & Luxembourg & $2,9 \%$ & $9,1 \%$ & $11,0 \%$ \\
\hline HU & Hungary & $11,7 \%$ & $12,5 \%$ & $13,0 \%$ \\
\hline MT & Malta & $0,2 \%$ & $8,0 \%$ & $10,0 \%$ \\
\hline NL & Netherlands & $4,3 \%$ & $7,4 \%$ & $14,0 \%$ \\
\hline AT & Austria & $31,0 \%$ & $33,4 \%$ & $34,0 \%$ \\
\hline PL & Poland & $8,7 \%$ & $11,3 \%$ & $15,0 \%$ \\
\hline PT & Portugal & $24,4 \%$ & $30,3 \%$ & $31,0 \%$ \\
\hline RO & Romania & $22,2 \%$ & $23,9 \%$ & $24,0 \%$ \\
\hline SI & Slovenia & $20,1 \%$ & $21,1 \%$ & $25,0 \%$ \\
\hline SK & Slovak Republic & $9,4 \%$ & $11,9 \%$ & $14,0 \%$ \\
\hline FI & Finland & $31,3 \%$ & $41,2 \%$ & $38,0 \%$ \\
\hline SE & Sweden & $47,9 \%$ & $54,6 \%$ & $49,0 \%$ \\
\hline $\mathbf{U K}$ & United Kingdom & $3,3 \%$ & $11,0 \%$ & $15,0 \%$ \\
\hline
\end{tabular}

In order to increase the degree of energy security, the EU carries out numerous actions on multiple levels, such as: diversification of energy resource providers, diversification of transport routes, interconnection of Member States in order to compensate for temporary interruptions on the principle of solidarity, as well as increasing the share of renewable resources within the energy mix. By adopting these measures the EU aims to ensure common energy security, but also to encourage Member States to strengthen their individual energy security, and the 
materialization of the Energy Union can be a huge step forward. At the same time, by adopting measures aimed at encouraging the use of energy from renewable sources, the EU is preparing for the end of the oil age, trying to make this transition as easy as possible and considering it a natural stage of society's evolution, not as a shock and as a major threat to the security of the Member States and of the Union as a whole.

\section{Conclusions}

Ensuring long-term energy security involves "a common approach, so long as it is not based on a colonial-type relationships, with the dominating and dominated contries, but with partnerships that bring benefits to all parties involved, and which contributes to the achievement of national and collective security" (Cîrdei, 2014, p. 151), because the shared vision and the sharing of the efforts allow to obtain significant results. The depletion of oil resources does not bring about the energy apocalypse but is a natural step in the evolution of society, because the world is aware of this and is already looking for alternative solutions, such as producing energy from renewable sources and trying to discover new sources of energy. The end of the oil age can also be hastened by the increasing concern of states to reduce the impact of human activity on the environment in order to reduce the effects of climate change. In any scenario, taking into account the increase of the population correlated with the increase of the consumption of energy resources, but also the development of the technology and the possibility of discovering new sources of hydrocarbons, mankind has about 50 years to prepare itself and to make the transition to a economy without oil.

Increasing energy efficiency in all areas must become a constant concern for all countries of the world, not just the EU, but this is harder to achieve in developing countries, which also have the largest population and the highest potential to increase the energy consumption. Developed states have benefited from all the conditions to reach a certain level of development and stability and they afford now to focus on issues related to reducing the impact on the environment and the production of energy from renewable sources.

The research in the field focuses on the discovery of alternative energy sources and on the improvement of the existing technologies, something observed in the field of transport, where electric vehicles are becoming more efficient and accessible as a price. Once this large consumer of energy from hydrocarbons domain will be able to make the switch to alternative energy sources, the importance of oil will decrease significantly, and the attention will have to be redirected on understanding and controlling the impact of alternative energy sources on the environment and on security of states and individual in order not to replace a known evil (hydrocarbons that contribute to increasing the amount of carbon in the atmosphere) with another element with a destructive potential, difficult to control and to anticipate.

\section{REFERENCES}

Chapman, I. (2014). The end of Peak Oil? Why this topic is still relevant despite recent denials. Energy Policy, Vol. 64, pp. 93-101, available at: http://dx.doi.org/10.1016/ j.enpol.2013.05.010i, accessed on 27 January 2020.

Cîrdei, I. A. (2014). National security and collective security from the perspective of ensuring energy security. Revista Academiei Forţelor Terestre, nr. 2 (74), Sibiu: Editura Academiei Forțelor Terestre „Nicolae Bălcescu”, p. 151. 
Elbassoussy, A. (2019). European energy security dilemma: major challenges and confrontation strategies. Review of Economics and Political Science, Vol. 4, Issue 4, 323-328.

ENI. (2019). World Oil Review, Vol. 1, 12-17, available at: https://www.eni.com/ en IT/investors/global-energy-scenarios/world-oil-gas-review-eng.page, accessed on 28 January 2020.

European Commission. (2012). Energy roadmap 2050. Luxembourg: Publications Office of the European Union, 3-5.

European Commission. (2018). Eurostat, Statistical data, available at: https://ec.europa. eu/eurostat/web/energy/data/shares, accessed on 02 February 2020.

European Parliament, Council of the European Union. (2009). Directive 2009/28/EC of the European Parliament and of the Council. Official Journal of the European Union, available at: https://eur-lex.europa.eu/legal-content/EN/ALL/?uri=CELEX:32009L0028, accessed on 02 February 2020.

European Parliament, Council of the European Union. (2018). Directive (EU) 2018/2001 of the European Parliament and of the Council of 11 December 2018 on the promotion of the use of energy from renewable sources (recast). Official Journal of the European Union, available at: https://eur-lex.europa.eu/legal\%20ontent/en/txt/?uri= uriserv:oj.1_2018.328.01.0082.01.eng\&toc $=0$ j:1:2018:328:toc, accessed on 02 February 2020.

Fusco, L. (2006). Peak oil theory, available at: www.ucs.mun.ca/ oilpower/ documents/Peakoil2-1.doc.pdf, accessed on 27 January 2020.

Hall, C., Tharakan, P., Hallock, J., Cleveland, C., \& Jefferson, M. (2003). Hydrocarbons and the evolution of human culture. Nature, Vol. 426, 318. 